\title{
Quantifying farmers' preferred agronomic traits and participatory bread wheat variety selection
}

\author{
AREGA Gashaw*, AKALU Gebru and AGEGNEHU Mekonnen \\ Sirinka Agricultural Research Center, North Wollo, P.O Box 74, Woldia, Ethiopia. \\ *Corresponding author. Email: argonlacomolza@gmail.com; Tel: +251-929231364.
}

\begin{abstract}
Copyright @ 2019 Arega et al. This article remains permanently open access under the terms of the Creative Commons Attribution License 4.0, which
\end{abstract} permits unrestricted use, distribution, and reproduction in any medium, provided the original work is properly cited.

Received 26th February, 2019; Accepted 16th April, 2019

\begin{abstract}
Farmers participatory bread wheat variety selection (PVS) was carried-out at major wheat producing areas of South Wollo, Ethiopia in the 2015 and 2016 cropping seasons. Fifteen recently released bread wheat varieties along with local variety were evaluated for yield and yield-related traits, with the objective of quantifying farmers' preferred agronomic traits and to associate farmers' qualitative selection with conventional breeding evaluation technique. The experiment was laid-out in Randomized Completely Block Design (RCBD) replicated three times, where farmer's field was used as a replication. Prior to evaluating the performance of the tested bread wheat varieties, progressive farmers listeddown and weighed the major farmers' preferred agronomic traits for bread wheat breeding and selection. Accordingly, they identified eight major quantitative and qualitative traits; categorized as cold tolerance, disease tolerance, earliness, kernel color, spike length, spike density, tillering potential and kernel boldness. Cold tolerance, disease tolerance and earliness were identified the major traits that predominantly determines wheat productivity and received $22 \%, 16 \%$ and $13 \%$ of farmers' selection criteria, respectively. Kernel color affects consumers' and market preferences, where white kernelled wheat grains fetch good market price. Thus, kernel color received $13 \%$ of farmers' selection index. On the other hand, spike length, spike density, tillering potential and kernel boldness received $11,9,10$ and $6 \%$ of the farmers' selection index, respectively. Bearing the set traits in mind, farmers evaluated the tested bread wheat varieties at maturity stage. Based on their overall evaluation, farmers preferred Danda'a, Ogolcho and King-bird at Legambo, Wogdie and Borena districts. On the other hand, Hidase was selected at Kelela district out-yielding the rest of the tested varieties. Breeders' quantitative analysis also confirmed results of farmers' qualitative selection, justifying the presence of farmers' untapped breeding and selection experiences that could be utilized in modern conventional breeding program. Therefore, breeders should involve farmers as main partners in crop breeding and selection program and augment conventional breeding skills with traditional farmers' knowledge.
\end{abstract}

Keywords: Bread wheat, farmers participatory, variety selection.

\section{INTRODUCTION}

Wheat is one of the major cereal crops grown in South Wollo, Ethiopia, covering about 108,000 hectares of arable land (CSA, 2016). Owing to various biotic and abiotic production constraints, production and productivity of wheat in South Wollo is below the national and regional average. Though several high yielding and disease resistant wheat varieties were released by the national and regional research institutes, farmers were reluctant to take up the newly released varieties. Hence, adoption of wheat varieties was not encouraging, claiming that the newly released varieties did not meet their preferences. Conventional breeders failed to seriously consider farmers' preferred traits as the major selection components during varietal development process. Moreover, the variety releasing requirements and heterogeneity between on-station and on-farm testing sites often lead to disparity between what is offered by breeders and what is desired by farmers (Witcombe and Virk, 1997).

Because of limited farmers' involvement in conventional 
breeding process, their needs and varietal preferences were not properly addressed. Conventional breeders may discard several breeding lines during the selection process, which the breeders considered the lines possess undesirable traits. Under farmers' sight, however, these traits may actually be desirable and the breeding lines may not be rejected (Abebe et al., 2005). There is substantial differences between farmers' and researchers' varietal selection methods, where farmers' variety choice decisions follow approximately Bayesian analytical approach (Namara and Manig, 2000).

Participating farmers in varietal development could help to incorporate farmers' selection criteria and augment conventional breeding. Hence, blending conventional breeding methods with farmers' varietal selection techniques would help to complement biological scientists' knowledge with farmers' rich experiences in developing farmers preferred and superior varieties and to facilitate efficient adoption of technologies. Farmers have untapped life-long agricultural experiences and know what traits they should focus on and which variety could fit to their environment. Such traditional knowledge is inherited orally from ancestors. Their traditional knowledge, particularly in crop varietal selection, is not well documented and did not receive research attention as yet.

Participatory Variety Selection (PVS) is widely advocated for efficient and fast adoption of technologies (Chimdesa et al., 2018). These days, national and regional research institutes are fully aware of the need to involve farmers in varietal development process. Making farmers to be part of the research and development intervention partners would ease acceptance and adoption of technology (Belay et al., 2006; Pandit et al., 2007; Witcombe et al., 1996). It overcomes the limitations of conventional breeding by offering farmers the chance to decide which varieties best suit their needs and environments without risking their livelihoods (Mustafa et al., 2006).

PVS is the active participation of farmers in developing superior variety that could fulfill their selection criteria. It is not only help in facilitating technological adoption and dissemination (Namara and Manig, 2000; Belay et al., 2006; Singh et al., 2014), but also advantageous in reducing research costs and shorten selection and evaluation processes (Belay et al., 2006; Orawu et al., 2013).

Farmers were efficient to quickly identify superior varieties possessing desirable traits (Orawu et al., 2013; Nkongolo et al., 2008; Namara and Manig, 2000; Abebe et al., 2005; Ceccarelli et al., 2003). The active participation of farmers in research process could promote fruitful discussion and cooperation between research scientists and farming communities in designing and implementing on-farm research (Chambers, 2005). Scientific insights of breeders in developing a variety could be integrated with the indigenous knowledge of farmers (Sperling et al., 1993). Exploiting and amalgamating farmers' selection criteria with conventional breeding techniques could complement breeders' knowledge and enhance their efficiencies in developing farmers preferred and superior bread wheat varieties.

Farmers employ multi-traits qualitative evaluation to select superior varieties to their specific environments (Seifu et al., 2018; Mancini et al., 2017; Namara and Manig, 2000). Bread wheat participatory variety selection has been conducted at different locations in Ethiopia (Chimdesa et al., 2018; Seifu et al., 2018; Mancini et al., 2017; Namara and Manig, 2000). However, information on farmers' preferred agronomic traits and quantification of their degree of contribution in bread wheat variety selection at major wheat producing areas of South Wollo, Ethiopia was very scanty. Hence, this experiment was conducted at major wheat producing areas of South Wollo, Ethiopia, with the objective of identifying and quantifying farmers' preferred agronomic traits in bread wheat breeding and selection, and associating farmers' participatory variety selection with conventional breeding techniques in developing superior bread wheat varieties.

\section{MATERIALS AND METHODS}

\section{Description of the study areas}

On-farm participatory bread wheat variety selection (PVS) was conducted at major wheat growing areas of Legambo, Wogdie, Borena and Kelela Districts, South Wollo, Ethiopia. Accessible and representative farmers' field were selected. Description of the study area is presented in Table 1. Legambo, Wogdie and Borena districts are generally characterized as relatively humid and the testing sites possess good water-holding capacity. Whereas, the testing site at Kelela is relatively dry and the soil type is generally characterized as sandy soil, poor water holding capacity which is liable for dry wind desiccation. The altitude of the testing sites ranged from 2462 to 2698 meter above sea level.

\section{Experimental materials}

Fifteen nationally and regionally released bread wheat varieties (Table 2) were tested for yield and yield-related traits in 2015 and 2016 cropping seasons. The experiment was laid-out in Randomized Completely Block Design (RCBD) replicated three times, where farmers' field was used as a replication. Varieties were row-planted on a plot size of $30 \mathrm{~m}^{2}$, with an inter-row spacing of $20 \mathrm{~cm}$.

\section{Experimental design and cultural practices}

Phosphorous and nitrogen fertilizers were applied in the form of Di-Ammonium Phosphate (DAP) and Urea, res- 
Table 1. Description of the study areas.

\begin{tabular}{llcccc}
\hline \multirow{2}{*}{ Environments } & \multirow{2}{*}{ Soil type } & \multicolumn{2}{c}{ Geographical coordinates } & \multirow{2}{*}{ Altitude (masl) } & \multirow{2}{*}{ Rainfall (mm) } \\
\cline { 3 - 4 } & & Latitude & Longitude & & \\
\hline Legambo & Vertisol & $10^{\circ} 77^{\prime} 74^{\prime \prime}$ & $38^{\circ} 92^{\prime} 40^{\prime \prime}$ & 2644 & 468 \\
Wogdie & Vertisol & $10^{\circ} 70^{\prime} 69^{\prime \prime}$ & $38^{\circ} 89^{\prime} 03^{\prime \prime}$ & 2462 & 551 \\
Borena & Litosol & $10^{\circ} 76^{\prime} 53^{\prime \prime}$ & $38^{\circ} 83^{\prime} 76^{\prime \prime}$ & 2698 & 502 \\
Kelela & Litosol & $10^{\circ} 66^{\prime} 32^{\prime \prime}$ & $39^{\circ} 14^{\prime} 92^{\prime \prime}$ & 2521 & 434 \\
\hline
\end{tabular}

*Total rainfall for the growing season (from June-November).

Table 2. List of experimental materials.

\begin{tabular}{llcl}
\hline No. & Variety name & Year of release & Releasing center \\
\hline 1 & Biqa & 2014 & KARC \\
2 & Danda'a & 2010 & KARC \\
3 & Dinknesh & 2007 & SRARC \\
4 & Hidase & 2012 & KARC \\
5 & Honqolo & 2014 & KARC \\
6 & King-bird & 2015 & KARC \\
7 & Local variety & - & Farmers' variety \\
8 & Madda Walabu & 1999 & SARC \\
9 & Mekelle-3 & 2012 & AARC \\
10 & Mekelle-4 & 2013 & AARC \\
11 & Ogolcho & 2012 & KARC \\
12 & Shorima & 2011 & KARC \\
13 & Sofumar & 1999 & SARC \\
14 & Sorra & 2013 & SRARC \\
15 & Tsehay & 2011 & DBARC \\
\hline
\end{tabular}

Where $\mathrm{KARC}=$ Kulumsa Agricultural Research Center, SRARC = Sirinka Agricultural Research Center, SARC = Sinana Agricultural Research Center, AARC= Alemata Agricultural Research Center, DBARC $=$ Debre-Birhan Agricultural Research Center.

pecttively as per the recommendations for vertisol and non vertisol areas. Soils with high vertic in nature received 104 $\mathrm{Kg} \mathrm{ha}^{-1} \mathrm{P}_{2} \mathrm{O}_{5}$ and $165 \mathrm{Kg} \mathrm{ha}^{-1} \mathrm{~N}_{2}$. Sandy soils, on the other hand, received $46 \mathrm{Kg} \mathrm{ha}^{-1} \mathrm{P}_{2} \mathrm{O}_{5}$ and $64 \mathrm{Kg} \mathrm{ha}^{-1} \mathrm{~N}_{2}$. Full dose of $\mathrm{P}_{2} \mathrm{O}_{5}$ was applied at planting time, while $\mathrm{N}_{2}$ was applied in split, half at planting and the remaining half at tillering stages. Other cultural activities were done uniformly for all treatments in a replication as required.

\section{Quantifying farmers' preferred traits}

Prior to varietal selection, discussion was held with participating farmers and development agents about the objective of the experiment and to set selection criteria for bread wheat breeding and variety selection. A total of 82 progressive farmers were participated in varietal selection in all the testing environments. Farmers were asked to listed-down their preferred agronomic traits that a superior bread wheat variety should possess. Then, they were given 25 labeled cards to weigh the degree of each trait's contribution to identify superior bread wheat. Farmers were oriented to weigh the traits based on the number of cards; more cards refers highly preferred traits and few for least preferred ones. Accordingly, farmers tallied the traits using labeled cards and weigh traits relative importance in bread wheat breeding and selection. The mean tallying scores of farmers for each trait were computed and quantified as the average farmers' selection index as per the following formula:

SI $(\%)=\frac{\mathrm{ST}_{\mathrm{i}}}{\mathrm{TS}_{\mathrm{a}}} * 100$

Where: SI (\%) = Farmers' Selection Index (\%) of a given trait, $\mathrm{ST}_{\mathrm{i}}=$ Total farmers' preference score for the $i^{\text {th }}$ trait, and $\mathrm{TS}_{\mathrm{a}}=$ Total farmers' preference score for all traits.

Then, farmers evaluated the performance of the tested bread wheat varieties against their preferred traits. The top three out-performing bread wheat varieties at each testing site was qualitatively identified and ranked using prefe- 
rence ranking technique.

\section{Quantitative evaluation of bread wheat varieties for grain yield and yield-related traits}

Data were recorded for yield and yield-related traits to scrutinize whether farmers' qualitative evaluation and variety selection is in agreement with breeders' quantitative analysis. Data on number of spikeletes spike1 (NSS) and number of kernels spike ${ }^{-1}$ (NKS) were recorded from five randomly taken plants from the central rows, which were tagged ahead of heading as per Gashaw et al. (2007). The data were averaged and recorded as the varietal performance. While data for thousand kernels weight (TKW), hectoliter weight (HLW) and grain yield (GY) were recorded from plots basis. TKW was recorded from composite kernels, where thousand clean kernels were randomly counted and weighed using sensitive balance. HLW was also recorded from composite kernels, where the volume of a kilogram of clean kernels was measured using GAC 2100 Grain Analysis Computer, Dickey-John Collaboration. Similarly, GY was also recorded with a similar fashion. Total clean kernels were weighed using sensitive balance and the weight was adjusted at $12.5 \%$ moisture content.

\section{Statistical procedures}

Farmers' preferred agronomic traits were analyzed using descriptive statistics taking the mean tallying scores. Then, preference ranking technique was employed to analyze farmers' bread wheat varietal selection. Based on the preference scoring result, the top three farmers' preferred bread varieties were identified for each testing environment. Quantitative data were analyzed using Genstat software, $18^{\text {th }}$ Edition. Duncan Multiple Range Test (DMRT) was used to separate treatment means. Genetic gain of farmers selected top-three varieties over the base population was analyzed using Pivot analysis of MS-Excel.

\section{RESULTS AND DISCUSSION}

\section{Quantifying farmers' preferred traits}

Farmers, by no means, did not rely on a single trait to identify superior bread wheat variety. They evaluate a given bread wheat variety from different agronomic and quality perspectives. However, the level of the traits' importance is not the same. Identifying and analyzing farmers' desirable bread wheat selection traits and weighing their degree of contribution to grain yield is very crucial to incorporate important traits for future breeding program. Farmers identified eight major quantitative and qualitative traits that is generally categorized as abiotic and biotic stress-related traits, yield-related and quality traits. Figure 1 depicted the major farmers' preferred traits in bread wheat improvement and their degree of contribution to grain yield.

\section{Cold tolerance}

Tolerance to cold stress was considered the overriding trait in wheat improvement, affecting the major economic traits. Bread wheat production and productivity in the study area, more often than not, is affected by cold/frost stress. Susceptibility of bread wheat variety to cold/frost stress would significantly affect both yield and quality traits. Frost is generally lethal, especially when it occurs at early flowering stage and when it freezes for long periods of time. Farmers in the study area are extremely concerned about the recurrent frost episodes. Significant yield loss was recorded when the frost incidence was very severe. Farmers, therefore, explicitly identified cold/frost tolerance as the first and major selection criteria in wheat breeding and selection.

Cold susceptible bread wheat variety is undesirable, regardless of how high-yielding and quality the variety is. Therefore, about $22 \%$ of farmers' selection index goes to cold tolerance (Figure 1). Wheat is very sensitive to freezing injury, particularly at reproductive stages, which begins with pollination during late boot or heading stages. Temperatures that are slightly below freezing can severely damage wheat at reproductive stages and greatly reduce grain yield. The flowering stage is the most freeze-sensitive stage in wheat. Small differences in temperature, duration of freezing exposure, or other conditions can cause large differences in amount of injury (Paulsen et al., 1982).

Developing frost tolerant wheat variety is very unlikely. However, mismatching flowering time and frosting period is the best technique to minimize risks associated with frost stress. Hence, adjusting planting time that would not synchronize with frosting time and/or growing bread wheat varieties that able to escape cold/frost incidence is advisable under frost-prone environments. Women farmers identified frost tolerance as a major agronomic trait in durum wheat variety selection at frost-prone areas of Geregera, North Wollo, Ethiopia (Mancini et al., 2017). Contrary to the present finding, Namara and Manig (2000) reported low selection index $(2.2 \%)$ for frost tolerance in bread wheat participatory selection at Arsi zone. Prevalence and severity of frost is location-specific. The low selection index for frost tolerance might be due to its low prevalence and severity at the targeted environments.

\section{Disease tolerance}

Wheat rusts are the major leaf diseases that seriously impede productivity and production of wheat in the study 


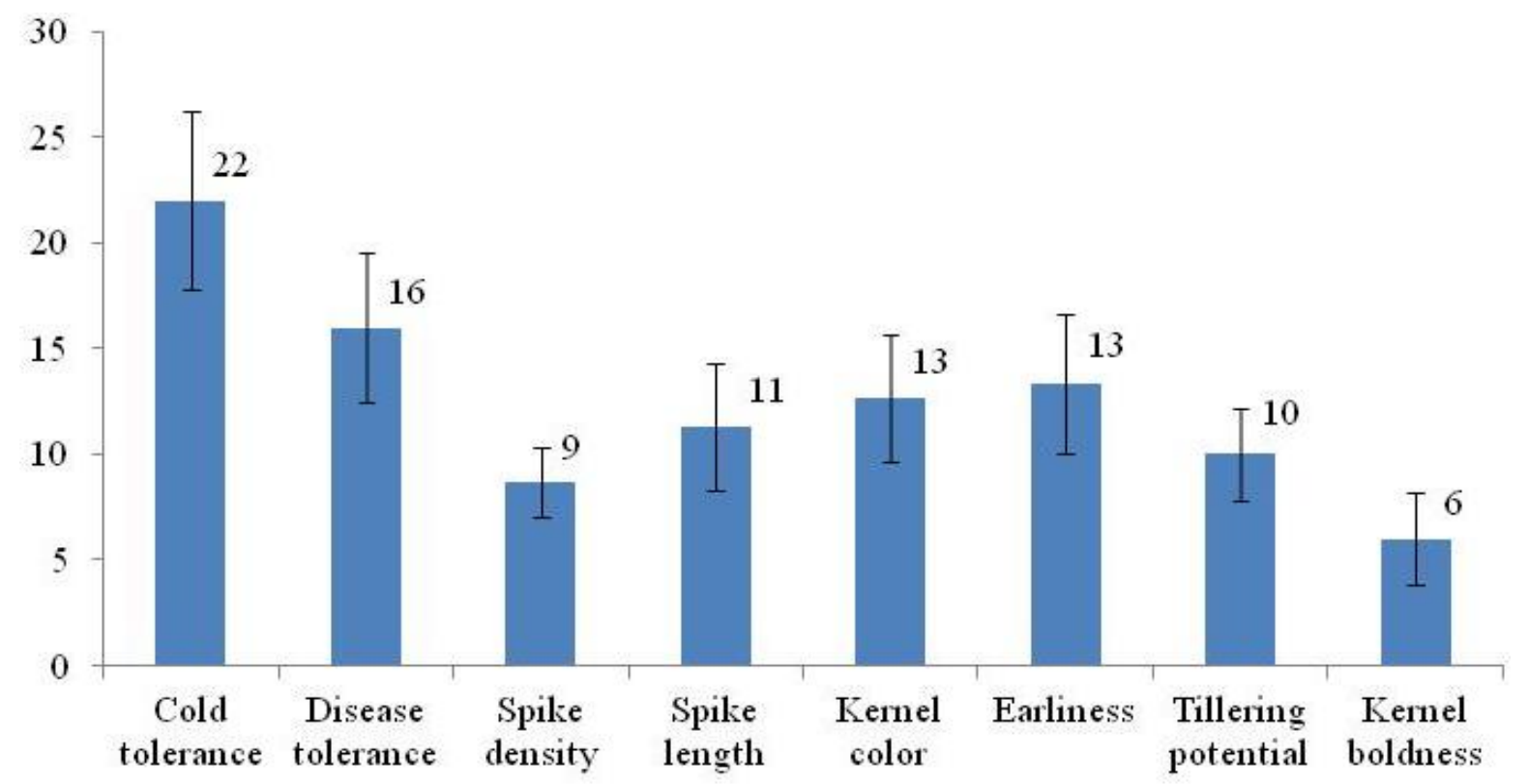

Figure 1. Farmers' preferred traits and their degree of contribution (\%) to bread wheat breeding and selection.

area. Rust tolerance ranked second, receiving $16 \%$ of farmers' selection index (Figure 1). International wheat research institutes (CIMMYT and ICARDA) incorporated disease resistance gene(s) to commercial wheat varieties. National and regional research institutes have benefitted from the segregant population to develop bread wheat varieties that would suit for diverse wheat growing environments, possessing resistant gene coupled with superior agronomic traits. There was significant variation in rust tolerance among wheat varieties, and the national and regional research institutes officially released numerous bread wheat varieties with specific and wider adaptability. However, with the frequent fungal mutations, unfortunately, rust tolerance is not durable, often broken within seven to ten years. Wheat breeders are always busy in screening rust tolerant bread wheat varieties and farmers are also worried about the devastating consequence of wheat rusts. Developing rust resistant and/or tolerant wheat varieties and protecting wheat fields with appropriate fungicides and exercising integrated disease management practices are generally recommended to minimize yield loss associated with wheat rusts. Similar to this finding, Seifu et al. (2018) and Mancini et al. (2017) reported disease and insect tolerance was the key trait and ranked first in bread wheat participatory variety selection.

\section{Earliness}

Bread wheat productivity is strongly correlated with the amount and distribution of rainfall within the growing period. Late onset, early termination and erratic distribution of rainfall coupled with recurrent frost episodes characterize the major bread wheat growing areas of South Wollo, Ethiopia ensuing significant yield loss. Development of bread wheat varieties that flower before frosting period and complete their physiological maturity earlier than the critical terminal moisture-stress period is very crucial. Hence, early maturity is an important trait in bread wheat breeding programs. Earliness, is therefore, the third farmers' preferred trait that an ideal bread wheat variety should possess in moisture deficit and frost- prone areas and hence received $13 \%$ of farmers' selection index (Figure 1).

Early maturing varieties escapes frost, terminal moisture stress and dry wind desiccation. Hence, breeders should consider earliness as a basic trait for future conventional wheat breeding. In agreement with the current finding, Basavaraj et al. (2015) found 10\% selection index for sorghum and pearl millet. Chimdesa et al. (2018), Mancini et al. (2017), Basavaraj et al. (2015), Vom Brocke et al. (2010) and lqbal et al. (2006) reported that early maturing wheat escapes frost damage, helps to withstand terminal moisture stress and allows farmers to grow under moisture-stressed environments.

\section{Kernel color}

Kernel color is one of the major quality attributes in bread wheat breeding and selection program, affecting consumers' and market preferences. Local market prefers white kernelled wheat, whereas flour factory did not have any colour preference as long as the other flour quality attributes are maintained. Notwithstanding its productivity, 
bread wheat variety should be white kernelled to be adopted by farmers. Hence, kernel colour received $13 \%$ of farmers' selection index (Figure1), implying the importance of this trait for future wheat breeding and selection program. In agreement with the current finding, Mancini et al. (2017) and Belay et al. (2006) reported seed color as the basic selection criterion in durum wheat and Tef variety selection, where white seeded varieties attract market preferences. Similarly, Vom Brocke et al. (2010) and Basavaraj et al. (2015) reported grain color as a primary trait in sorghum breeding that could significantly affect consumers' preferences and technological adoption, receiving $18.7 \%$ of the selection index. Hence, conventional breeders should seriously consider farmers' and local market's kernel colour preferences.

\section{Yield-components}

Yield is a complex quantitative trait. Its phenotypic expression depends on the cumulative actions of several genes, and highly influenced by environmental factors. The influence of non-genetic factors on grain yield is very strong. Hence, selection of varieties based on grain yield alone may not always be successful. Easily measurable and highly heritable traits that have strong genotypic correlation with grain yield, which is termed as yieldcomponents, could be used as an indirect selection criterion to select high yielding varieties (Gashaw et al., 2010). Farmers identified four major bread wheat yieldcomponents and indexed them accordingly as per their relative contribution to grain yield.

\section{Spike length}

In normal situations, where there is no serious environmental stresses in the growing season, farmers can easily and visually identify high-yielding bread wheat varieties. Using spike length as a selection marker, bread wheat varieties possessing long spike are considered high yielding under normal environmental conditions and when other yield components remained constant. From their cumulative experiences, farmers are unhesitant to pick up spike length as an important trait in bread wheat breeding and selection. They knew the presence of strong correlation between spike length and grain yield, implying the need to consider spike length as a major yieldcomponents in bread wheat varietal selection. Thus, spike length received $11 \%$ of farmers' selection weight (Figure 1). In agreement with farmers' selection criterion, conventional breeders also use spike length as major trait in bread wheat breeding and selection program. Moreover, Seifu et al. (2018) indicated that spike size is one of the most important farmers preferred traits in bread wheat breeding and selection at Arsi Zone, Oromia Regional State, Ethiopia.

\section{Spike density}

Spike density is the ratio of number of spikelets spike ${ }^{-1}$ to spike length. Though spike length is one of the major yield components in bread wheat genetic improvement, spike length per se may not always directly indicate high-yielding varieties. Bread wheat varieties with long spike length but dispersed spikelets spike- ${ }^{-1}$ considered inferior in grain yield and hence undesirable. Bread wheat varieties possessing long spike with denser spikelets spike ${ }^{-1}$ would have higher grain yield than short spike and dispersed spikelets spike ${ }^{-1}$, if other genetic and non-genetic factors are kept constant.

Farmers traditionally use spike density to identify and select superior bread wheat variety, owing to its importance in bread wheat genetic improvement, providing $9 \%$ of the selection weight (Figure 1). Characterizing and evaluating bread wheat genotypes for spike characteristics should be a prerequisite in bread wheat breeding and selection program. Hence, conventional breeders should learn from farmers' long and unexploited breeding experiences to rapidly screen farmers' preferred bread wheat varieties based on their preferred traits.

\section{Tillering potential}

Lateral shoots arising from the primary shoot are termed as tillers. Not all tillers are productive and bread wheat varieties possessing numerous non-productive tillers are undesirable. Non-productive tillers compete with the main shoot for nutrients and sunlight and had negative influence on grain yield. Productive tillers, on the other hand, improve grain yield. Hence, bread wheat varieties possessing reasonable number of productive tillers per shoot are considered high-yielding.

Farmers considered tillering potential as one of the major traits in selecting superior bread wheat variety, receiving $10 \%$ of farmers' selection index (Figure 1). Seifu et al. (2018) found tillering capacity as the third important farmers' selection criteria in bread wheat variety selection at major wheat producing areas of Arsi, Oromia Regional State, Ethiopia. The nature and number of tillers are one of the key indicators of high-yielding bread wheat genotypes. Conventional breeders could use tillering potential as a major agronomic trait and exercise early and advanced generation screening of bread wheat genotypes for high grain yield.

\section{Kernel boldness}

Wheat kernel boldness is positively associated with grain yield. Farmers and customers prefer bolded kernels. Thus, kernel boldness received $6 \%$ of farmers' selection weight in bread wheat breeding and selection program (Figure 1).

Grain yield, a quantitative economic trait, is affected by many genes, each having minor effect. Moreover, it is 
strongly affected by environmental factors. Being grain yield is a polygenic trait, direct selection of bread wheat varieties based on grain yield alone may not be successful. Yield components that are easily measurable and highly heritable traits and that have strong correlation with grain yield could be used as indirect selection criterion (Gashaw et al., 2010). Similar to conventional breeders, farmers are able to identify yield components that would significantly affect grain yield. In agreement with the current finding, Ceccarelli et al. (2000) reported the efficiency of farmers to identify desirable traits in barley breeding and selection and they were successful in identifying high yielding barley varieties. In agreement with the current finding, Chimdesa et al. (2018) reported disease resistant, productivity, earliness, spike length and tillering capacity as the major farmers' preferred traits to select superior bread wheat varieties. Grain size is one of the major farmers preferred traits in sorghum. Bold sorghum grains have high market preference and fetch higher price and thus received $20.85 \%$ of the selection index (Basavaraj et al., 2015).

\section{Participatory bread wheat variety selection}

Cold and disease tolerance, earliness, kernel color, spike length, spike density, tillering potential and kernel boldness were identified as the major farmers' preferred traits to select ideal bread wheat variety. Bearing the set traits in mind, farmers independently evaluated bread wheat varieties at maturity time using preference ranking technique. Varietal preference in all environment, except at Kelela, were almost similar. Based on the overall farmers' qualitative evaluation, Danda'a outsmarted the rest of the bread wheat varieties at Legambo, Wogdie and Borena districts, scoring 41,39 and $35 \%$, respectively. Variety Ogolcho ranked second scoring 31,32 and 26 at Legambo, Wogdie and Borena districts, respectively. Whereas, King-bird is the third preferred wheat variety at Legambo, Wogdie and Borena districts, scoring 22, 24 and $28 \%$, respectively (Figure 2 ).

Wheat rust is the major biotic constraints that severely affect wheat production. Currently, cluster farming is becoming popular in Ethiopia and variety Danda'a is widely cultivated at major bread wheat growing areas of South Wollo, Ethiopia. Relying on a single wheat variety and mono-cropping year after year is a risky business for wheat farmers, if there is a rust outbreak. Hence, developing alternative bread wheat variety that is as high yielding as Danda'a is the best strategy to minimize the risk. Ogolcho and King-bird fulfilled farmers' selection criteria and could be alternatively cultivated at different wheat clusters at Legambo, Wogdie and Borena districts. On the other hand, Hidase was selected as the best bread wheat variety at Kelela that outweighed the rest of the tested bread wheat varieties in most of the traits considered, followed by King-bird and Ogolcho (Figure 2). King-bird is a short stature, early maturing, bold and white kernelled bread wheat variety. It escapes terminal moisture stress and frost/cold incidence. It could be, therefore, cultivated in light soil, terminal moisture-stress and frost/cold prone environments.

\section{Quantitative evaluation of bread wheat varieties for yield and yield-related traits}

The performance of bread wheat varieties for grain yield and yield-related traits are presented in Table 3 as follows:

\section{Bread wheat varietal variation for grain yield}

Variety Ogolcho, Madda Walabu, Tsehay, Dinknesh, Hidase and Danda'a out-smarted in grain yield at Legambo, recording mean grain yield ranging from 5724 to $6024 \mathrm{Kg} \mathrm{ha}^{-1}$ (Table 3). In agreement with farmers' selection, quantitative analysis also depicted that Ogolcho and Danda'a showed superior performance in grain yield. Madda Walabu is a high yielding but late-maturing bread wheat variety that could suit to high potential environments. Growing of late-maturing bread wheat variety under moisture deficit environments, however will be exposed to terminal moisture stress, yielding little or no harvest at times where the stress is very severe. Thus, late maturing variety is unbefitting under terminal moisturestress environments of South Wollo, Ethiopia, no matter how high yielding the variety's genetic potential is.

On the other hand, Tsehay had extremely short maturity period. However, its flowering time is coincided with the frosting period, making the variety susceptible to freezing injury. Generally, pollen-grains are very sensitive for extreme cold stress. Flowering at the major cold incidence period would kill pollen grains, resulting male sterility. Farmers preferred variety that able to escape the frost/cold stress, via mis-matching flowering and frosting periods. Farmers did not prefer variety Tsehay because of its flowering time coincided with cold/frosting period.

Variety Dinknesh is an early maturing, yellow-rust resistant and high-yielding bread wheat variety. However, Dinknesh is not under farmers' preference list because of its brownish kernel color. Farmers preferred white kernelled wheat to meet the local market demand and to fetch good market price. Hidase, on the other hand, is a high-yielding bread wheat variety but very sensitive to stem rust, that is why farmers are reluctant to select the aforementioned bread wheat varieties in spite of their yielding potential. Therefore, farmers have good reasons to select a variety for their environment. In agreement with farmers' qualitative selection, quantitative analysis also identified Ogolcho, Danda'a and King-bird as superior bread wheat varieties for Legambo and similar environments.

At Wogdie, on the other hand, Mekele-3, Hidase, Mekelle-4, Honqolo, Tsehay, Ogolcho and Danda'a out- 

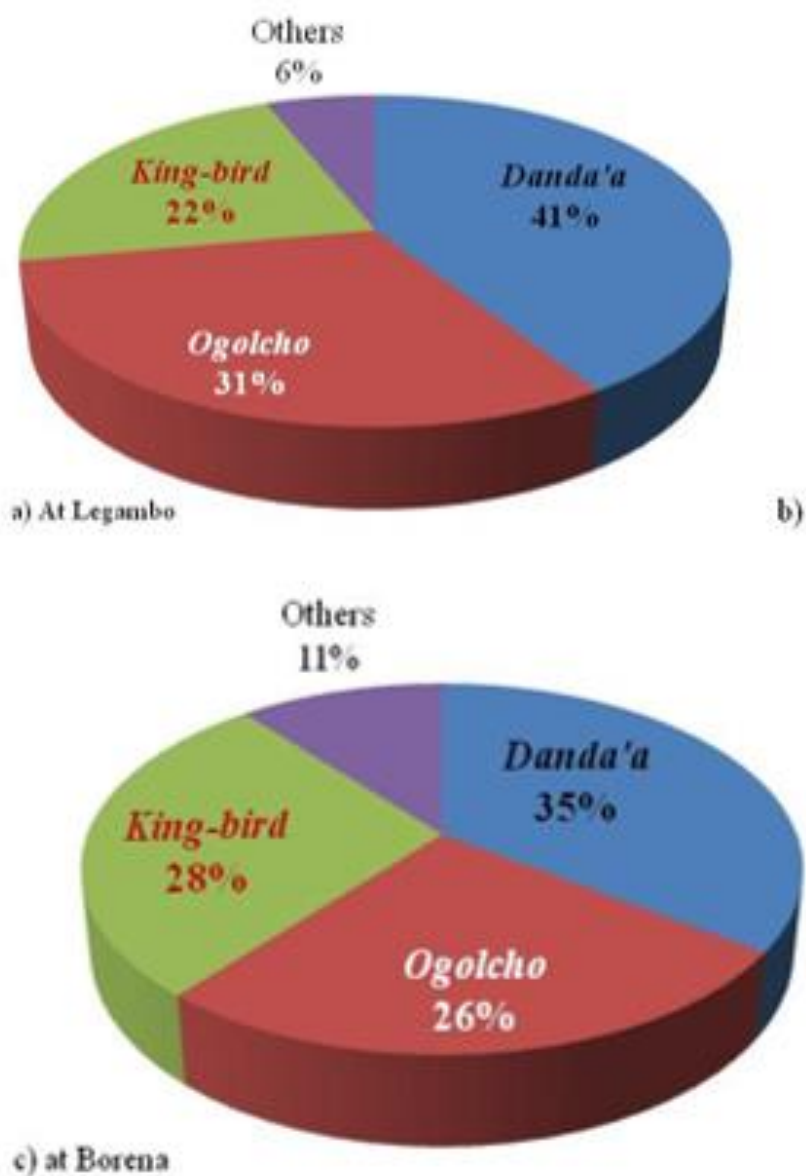

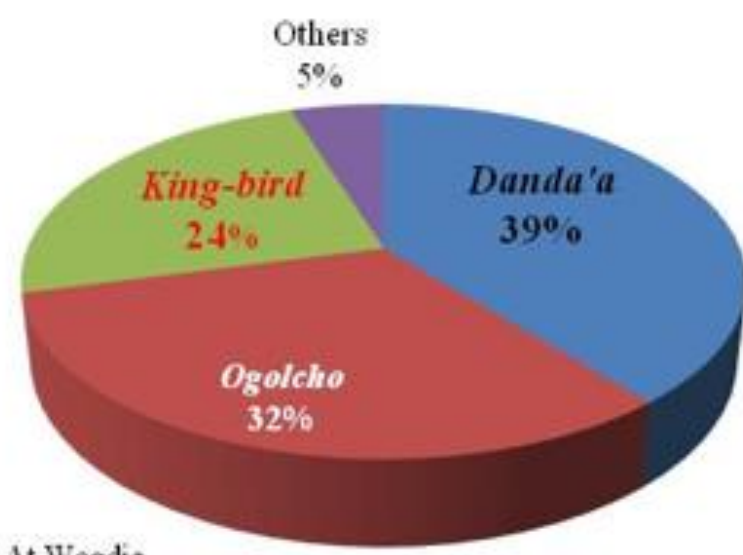

b) At Wogdic

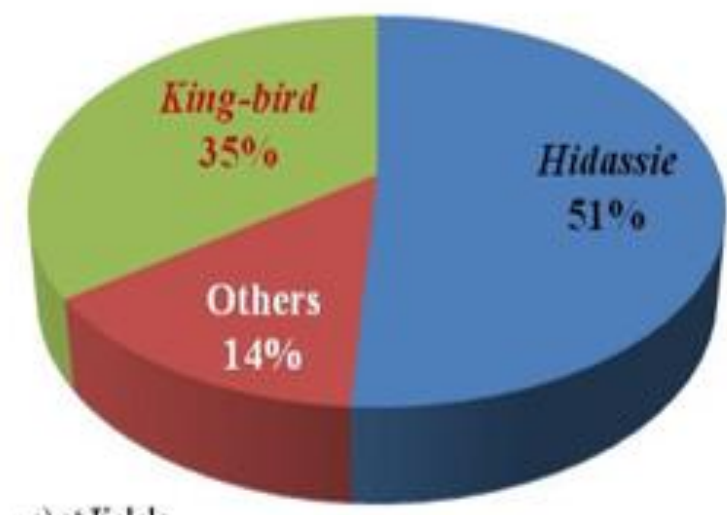

c) at Kelela

Figure 2. Farmers preferred bread wheat varieties at a) Legambo, b) Wogdie, c) Borena and d) Kelela.

Table 3. Performance of bread wheat varieties for grain yield across locations.

\begin{tabular}{lccccc}
\hline Variety & Legambo & Wogdie & Borena & Kelela & Mean \\
\hline Biqa & $5376^{\mathrm{b}-\mathrm{d}}$ & $4459^{\mathrm{b}}$ & $4959^{\mathrm{b}-\mathrm{e}}$ & $2083^{\mathrm{c}}$ & $4667^{\mathrm{bc}}$ \\
Danda'a & $5724^{\mathrm{d}-\mathrm{f}}$ & $4828^{\mathrm{bc}}$ & $5021^{\mathrm{ce}}$ & $1908^{\mathrm{a}}$ & $4866^{\mathrm{bc}}$ \\
Dinknesh & $5470^{\mathrm{c}-\mathrm{f}}$ & $4763^{\mathrm{bc}}$ & $4809^{\mathrm{b}-\mathrm{d}}$ & $3110^{\mathrm{h}}$ & $4831^{\mathrm{bc}}$ \\
Hidase & $5745^{\mathrm{d}-\mathrm{f}}$ & $5277^{\mathrm{bc}}$ & $4397^{\mathrm{b}}$ & $3717^{\mathrm{i}}$ & $4966^{\mathrm{bc}}$ \\
Honqolo & $4856^{\mathrm{b}}$ & $4969^{\mathrm{bc}}$ & $4756^{\mathrm{b}-\mathrm{d}}$ & $3085^{\mathrm{h}}$ & $4651^{\mathrm{bc}}$ \\
King-bird & $5405^{\mathrm{b}-\mathrm{d}}$ & $4289^{\mathrm{b}}$ & $5489^{\mathrm{ef}}$ & $2939^{\mathrm{g}}$ & $4904^{\mathrm{bc}}$ \\
Local variety & $3968^{\mathrm{a}}$ & $3269^{\mathrm{a}}$ & $3572^{\mathrm{a}}$ & $1986^{\mathrm{b}}$ & $3460^{\mathrm{a}}$ \\
Madda Walabu & $6009^{\mathrm{ef}}$ & $4785^{\mathrm{bc}}$ & $5056^{\mathrm{c}-\mathrm{e}}$ & $2057^{\mathrm{c}}$ & $4980^{\mathrm{bc}}$ \\
Mekelle-3 & $5424^{\mathrm{b}-\mathrm{e}}$ & $5610^{\mathrm{c}}$ & $4660^{\mathrm{bc}}$ & $2742^{\mathrm{e}}$ & $4913^{\mathrm{bc}}$ \\
Mekelle-4 & $5378^{\mathrm{b}-\mathrm{d}}$ & $5201^{\mathrm{bc}}$ & $6066^{\mathrm{g}}$ & $2831^{\mathrm{f}}$ & $5285^{\mathrm{c}}$ \\
Ogolcho & $6024^{\mathrm{f}}$ & $4867^{\mathrm{bc}}$ & $5972^{\mathrm{fg}}$ & $2749^{\mathrm{e}}$ & $5386^{\mathrm{c}}$ \\
Shorima & $4931^{\mathrm{bc}}$ & $4631^{\mathrm{bc}}$ & $3681^{\mathrm{a}}$ & $2778^{\mathrm{ef}}$ & $4209^{\mathrm{ab}}$ \\
Sofumar & $5650^{\mathrm{d}-\mathrm{f}}$ & $4577^{\mathrm{b}}$ & $4517^{\mathrm{bc}}$ & $2255^{\mathrm{d}}$ & $4652^{\mathrm{bc}}$ \\
Sorra & $5587^{\mathrm{d}-\mathrm{f}}$ & $4437^{\mathrm{b}}$ & $5362^{\mathrm{de}}$ & $3115^{\mathrm{h}}$ & $4982^{\mathrm{bc}}$ \\
Tsehay & $6001^{\mathrm{ef}}$ & $4916^{\mathrm{bc}}$ & $5136^{\mathrm{c}-\mathrm{e}}$ & $2232^{\mathrm{d}}$ & $5053^{\mathrm{bc}}$ \\
Mean & 5437 & 4725 & 4897 & 2639 & 4787 \\
CV $(\%)$ & 5.6 & 8.6 & 6.7 & 1.2 & 19.8 \\
\hline
\end{tabular}


Table 4. Performance of bread wheat varieties for number of spikelets per spike across locations.

\begin{tabular}{|c|c|c|c|c|c|}
\hline Variety & Legambo & Wogdie & Borena & Kelela & Mean \\
\hline Biqa & $17.0^{\mathrm{bc}}$ & $16.2^{\mathrm{cd}}$ & 17.0 & $17.2^{\mathrm{bc}}$ & $16.9^{b-d}$ \\
\hline Danda'a & $17.4^{\mathrm{bc}}$ & $17.7^{b}$ & 18.5 & $17.4^{\mathrm{bc}}$ & $17.8^{\mathrm{b}}$ \\
\hline Dinknesh & $17.5^{\mathrm{bc}}$ & $17.3^{b c}$ & 17.1 & $17.2^{\mathrm{bc}}$ & $17.3^{b c}$ \\
\hline Hidase & $16.3^{c}$ & $15.5^{\mathrm{cd}}$ & 16.2 & $18.4^{\mathrm{ef}}$ & $16.3^{\text {cd }}$ \\
\hline Honqolo & $16.9^{b c}$ & $17.3^{b c}$ & 17.4 & $19.2^{\mathrm{fg}}$ & $17.5^{\mathrm{bc}}$ \\
\hline King-bird & $17.6^{\mathrm{bc}}$ & $16.54^{b-d}$ & 17.0 & $19.2^{\mathrm{g}}$ & $17.2^{\mathrm{bc}}$ \\
\hline Local variety & $18.6^{\mathrm{ab}}$ & $15.9^{b-d}$ & 16.5 & $17.8^{\mathrm{c}-\mathrm{e}}$ & $17.1^{b-d}$ \\
\hline Madda Walabu & $16.9^{b c}$ & $17.0^{\mathrm{b}-\mathrm{d}}$ & 18.8 & $17.6^{\mathrm{cd}}$ & $17.7^{\mathrm{b}}$ \\
\hline Mekelle-3 & $17.2^{\mathrm{bc}}$ & $15.7^{\mathrm{cd}}$ & 16.6 & $17.6^{\mathrm{cd}}$ & $16.3^{b-d}$ \\
\hline Mekelle-4 & $17.1^{\mathrm{bc}}$ & $16.6^{b-d}$ & 17.4 & $18.2^{\mathrm{de}}$ & $17.2^{\mathrm{bc}}$ \\
\hline Ogolcho & $17.2^{\mathrm{bc}}$ & $16.5^{\mathrm{b}-\mathrm{d}}$ & 17.0 & $16.8^{\mathrm{b}}$ & $17.0^{\mathrm{b}-\mathrm{d}}$ \\
\hline Shorima & $17.3^{b c}$ & $16.5^{\mathrm{b}-\mathrm{d}}$ & 16.6 & $16.8^{b}$ & $16.8^{\mathrm{b}-\mathrm{d}}$ \\
\hline Sofumar & $19.4^{\mathrm{a}}$ & $20.3^{a}$ & 18.5 & $19.6^{g}$ & $19.4^{a}$ \\
\hline Sorra & $16.1^{\mathrm{c}}$ & $15.4^{d}$ & 16.2 & $15.6^{\mathrm{a}}$ & $15.9^{d}$ \\
\hline Tsehay & $16.7^{\circ}$ & $15.8^{\mathrm{cd}}$ & 16.2 & $17.2^{\mathrm{bc}}$ & $16.4^{\text {cd }}$ \\
\hline Mean & 17.3 & 16.7 & 17.1 & 17.7 & 17.2 \\
\hline CV (\%) & 5.2 & 4.5 & 6.2 & 1.6 & 6.6 \\
\hline
\end{tabular}

yielded the rest of bread wheat varieties. Farmers recognized kernel boldness as a basic parameter to screen bread wheat varieties. In spite of its high-yielding potential, Mekelle-3 is relatively small kernelled variety that did not satisfy farmers' kernel size preference. On the other hand, the performance of Mekelle-4 was inconsistent across farmers' fields. Moreover, it is moderately susceptible to yellow rust. Farmers are very concerned about the devastating effect of yellow rust. Mekelle-4 might be totally wiped-out if there is yellow rust outbreak. Farmers are very smart to identify rust resistant bread wheat variety. On the other hand, Honqolo had nonuniform and dispersed spikelets spike ${ }^{-1}$, which farmers locally in Amharic called Yewusha tris (Dog teeth). Farmers believed uniform and denser spikletes are good indicator of high-yielding bread wheat variety. Varieties possessing Yewusha tris type spikelets are not preferred. In general, Ogolcho and Danda'a are both high-yielding varieties and fulfilled farmers preferences.

At Borena, on the one hand, Mekele-4 and Ogolcho outyielded the rest of the varieties followed by King-bird and Danda'a (Table 3). Ogolcho, Danda'a and King-bird are consistently out-performing across diverse environments and they are also farmers preferred varieties. Hidase gave relatively better grain yield at Kelela, where the environment is characterized as sandy soil with low water holding capacity and suffered cold stress at heading stage. Quantitative analysis also confirmed farmers' qualitative selection, implying the presence of farmers' unexploited breeding and selection experiences. Hence, conventional breeders should involve farmers as main partners in varietal breeding and selection program.

\section{Bread wheat varietal variation for number of spikelets spike $^{-1}$}

Significant variation was observed among bread wheat varieties for number of spikelets spike-1 (Table 4) in all the testing environments, except at Borena. Being number of spikelets spike- ${ }^{-1}$ is a yield component, it is directly and positively associated with grain yield. Sofumar consistently showed more number of spikelets spike-1 followed by Danda'a, Madda Walabu, Honqolo, Dinknesh and Kingbird. The two most farmers' preferred bread wheat varieties; Danda'a and King-bird exhibited the highest number of spikelets spike ${ }^{-1}$.

\section{Bread wheat varietal variation for number of kernels spike $^{-1}$}

Number of kernels spike ${ }^{-1}$ is one of the basic yield components in bread wheat breeding and selection program which is directly and positively associated with grain yield. Significant variation was exhibited among bread wheat varieties for number of kernels spike-1 across environments, except at Wogdie (Table 5). Danda'a, Ogolcho and King-bird reasonably had the highest number kernels spike ${ }^{-1}$, indicating their superb yielding potential. Using number of kernels spike-1 as selection criteria, farmers easily identified Danda'a and Ogolcho as the best and high yielding bread wheat varieties. Farmers' qualitative evaluation is also confirmed by quantitative analysis. This is not simply a coincidence, rather showed the presence of farmers' unutilized breeding and selection 
Table 5. Performance of bread wheat varieties for Number of kernels per spike across locations.

\begin{tabular}{|c|c|c|c|c|c|}
\hline Variety & Legambo & Wogdie & Borena & Kelela & Mean \\
\hline Biqa & $52.8^{a}$ & 41.6 & $53.0^{\mathrm{ab}}$ & $42.0^{9}$ & $49.2^{\mathrm{a}-\mathrm{c}}$ \\
\hline Danda'a & $49.5^{a-d}$ & 52.6 & $55.0^{\mathrm{a}}$ & $49.3^{c}$ & $52.0^{a}$ \\
\hline Dinknesh & $43.7^{\mathrm{cd}}$ & 46.0 & $41.6^{d}$ & $36.8^{\mathrm{i}}$ & $42.7^{\mathrm{e}}$ \\
\hline Hidase & $52.9^{a}$ & 53.1 & $50.2^{\mathrm{a}-\mathrm{d}}$ & $54.8^{\mathrm{a}}$ & $52.3^{a}$ \\
\hline Honqolo & $46.9^{a-d}$ & 48.5 & $51.4^{\mathrm{a}-\mathrm{c}}$ & $54.4^{\mathrm{a}}$ & $50.4^{a-c}$ \\
\hline King-bird & $51.7^{\mathrm{a}-\mathrm{c}}$ & 53.6 & $45.1^{\mathrm{b}-\mathrm{d}}$ & $54.8^{\mathrm{a}}$ & $49.7^{\mathrm{a}-\mathrm{c}}$ \\
\hline Local variety & $41.5^{d}$ & 39.3 & $32.7 e$ & $34.2^{k}$ & $36.9^{f}$ \\
\hline Madda Walabu & $43.9^{b-d}$ & 45.1 & $55.2^{\mathrm{a}}$ & $40.6^{h}$ & $47.6^{a-e}$ \\
\hline Mekelle-3 & $51.8^{\mathrm{a}-\mathrm{c}}$ & 42.9 & $48.9^{a-d}$ & $21.2^{1}$ & $45.5^{\mathrm{b}-\mathrm{e}}$ \\
\hline Mekelle-4 & $46.1^{a-d}$ & 48.5 & $53.3^{\mathrm{ab}}$ & $42.6^{f}$ & $48.7^{a-e}$ \\
\hline Ogolcho & $52.6^{a}$ & 50.6 & $50.8^{\mathrm{a}-\mathrm{c}}$ & $50.0^{b}$ & $51.3^{\mathrm{ab}}$ \\
\hline Shorima & $46.3^{a-d}$ & 42.7 & $47.5^{a-d}$ & $40.4^{\mathrm{h}}$ & $45.3^{b-e}$ \\
\hline Sofumar & $44.1^{b-d}$ & 48.0 & $42.7^{\mathrm{cd}}$ & $46.0^{d}$ & $44.7^{\mathrm{c}-\mathrm{e}}$ \\
\hline Sorra & $42.5^{d}$ & 42.7 & $48.0^{\mathrm{a}-\mathrm{d}}$ & $35.5^{j}$ & $43.6^{\text {de }}$ \\
\hline Tsehay & $52.1^{\mathrm{ab}}$ & 48.5 & $43.0^{\text {cd }}$ & $44.4^{e}$ & $47.4^{\mathrm{a}-\mathrm{e}}$ \\
\hline Mean & 47.9 & 46.9 & 47.9 & 43.13 & 47.2 \\
\hline CV (\%) & 8.9 & 9.4 & 9.6 & 0.6 & 12.4 \\
\hline
\end{tabular}

Table 6. Performance of bread wheat varieties for thousand kernels weight $(\mathrm{g})$ across locations.

\begin{tabular}{|c|c|c|c|c|c|}
\hline Variety & Legambo & Wogdie & Borena & Kelela & Mean \\
\hline Biqa & $41.5^{\mathrm{ab}}$ & $40.5^{\mathrm{de}}$ & $34.0^{\text {cd }}$ & $23.9^{b}$ & $36.8^{b}$ \\
\hline Danda'a & $43.8^{\mathrm{a}}$ & $46.4^{\mathrm{a}-\mathrm{c}}$ & $38.9^{a-d}$ & $25.0^{\mathrm{cd}}$ & $40.7^{\mathrm{cd}}$ \\
\hline Dinknesh & $38.2^{\mathrm{bc}}$ & $43.7^{\mathrm{b}-\mathrm{e}}$ & $36.8^{a-d}$ & $28.8^{g}$ & $37.9^{b c}$ \\
\hline Hidase & $39.6^{b}$ & $44.6^{\mathrm{a}-\mathrm{d}}$ & $37.3^{\mathrm{a}-\mathrm{d}}$ & $33.2^{i}$ & $39.3^{c}$ \\
\hline Honqolo & $25.6^{d}$ & $43.0^{\mathrm{b}-\mathrm{e}}$ & $34.2^{b-d}$ & $24.1^{b c}$ & $32.2^{\mathrm{a}}$ \\
\hline King-bird & $35.4^{\mathrm{c}}$ & $42.6^{b-e}$ & $38.9^{a-d}$ & $28.1^{\mathrm{fg}}$ & $37.4^{b}$ \\
\hline Local variety & $23.7^{d}$ & $40.0^{e}$ & $33.4^{\mathrm{cd}}$ & $26.11^{\mathrm{e}}$ & $30.9^{a}$ \\
\hline Madda Walabu & $42.4^{\mathrm{a}}$ & $48.2^{\mathrm{a}}$ & $44.3^{a}$ & $24.3^{b c}$ & $42.3^{d}$ \\
\hline Mekelle-3 & $36.0^{c}$ & $40.1^{\mathrm{e}}$ & $31.0^{\mathrm{d}}$ & $24.7^{\mathrm{b}-\mathrm{d}}$ & $34.0^{\mathrm{ab}}$ \\
\hline Mekelle-4 & $42.4^{\mathrm{a}}$ & $46.7^{\mathrm{ab}}$ & $39.4^{a-d}$ & $27.7^{f}$ & $40.7^{\text {cd }}$ \\
\hline Ogolcho & $40.9^{a b}$ & $44.1^{\mathrm{a}-\mathrm{e}}$ & $40.7^{a-c}$ & $24.8^{b-d}$ & $39.8^{c}$ \\
\hline Shorima & $36.7^{c}$ & $42.8^{\mathrm{b}-\mathrm{e}}$ & $31.74^{d}$ & $25.4^{\mathrm{de}}$ & $35.2^{\mathrm{ab}}$ \\
\hline Sofumar & $38.9^{b}$ & $44.2^{\mathrm{a}-\mathrm{e}}$ & $35.7^{b-d}$ & $24.84^{b-d}$ & $37.5^{b}$ \\
\hline Sorra & $44.5^{\mathrm{a}}$ & $45.1^{a-c}$ & $42.5^{\mathrm{ab}}$ & $32.2^{\mathrm{h}}$ & $42.6^{d}$ \\
\hline Tsehay & $38.4^{\mathrm{b}}$ & $42.3^{c-e}$ & $37.9^{a-d}$ & $20.7^{a}$ & $37.1^{b}$ \\
\hline Mean & 37.9 & 43.7 & 37.1 & 26.26 & 37.6 \\
\hline CV (\%) & 14.4 & 4.0 & 11.6 & 1.5 & 8.3 \\
\hline
\end{tabular}

skills that conventional breeders should make use of it for future bread wheat improvement program.

\section{Bread wheat varietal variation for thousand kernels weight}

The performance of bread wheat varieties for thousand kernels weight (TKW) is presented in Table 6. Significant variation was displayed among bread wheat varieties and environments for TKW, indicating the importance of genetic and non-genetic factors to develop bold kernelled bread wheat varieties.

At Legambo, TKW ranged from 23.7 to $44.5 \mathrm{~g}$, where maximum TKW was recorded from variety Sorra $(43.8 \mathrm{~g})$ followed by Danda'a (43.8 g), Mekelle-4 (42.4 g) and Madda Walabu (42.4 g). The variation for TKW, however, is very narrow at Wogdie, ranging from 40 to $48.2 \mathrm{~g}$. Madda Walabu had the highest TKW (48.2 g) followed by Mekelle-4 (46.7 g), Danda'a (46.4 g) and Sorra (45.1 g).

At Borena, TKW ranged from $31.7 \mathrm{~g}$ (Shorima) to $44.3 \mathrm{~g}$ (Madda Walabu). Variety Sorra, Ogolcho, Danda'a and 
Table 7. Performance of bread wheat varieties for Hectoliter weight $\left(\mathrm{kg} \mathrm{hL}^{-1}\right)$ across locations.

\begin{tabular}{lccccc}
\hline Variety & Legambo & Wogdie & Borena & Kelela & Mean \\
\hline Biqa & $81.0^{\mathrm{a}}$ & $81.4^{\mathrm{ab}}$ & 78.8 & $75.0^{\mathrm{de}}$ & $79.0^{\mathrm{ab}}$ \\
Danda'a & $78.9^{\mathrm{ab}}$ & $78.4^{\mathrm{c}}$ & 78.4 & $74.0^{\mathrm{b}}$ & $77.4^{\mathrm{b}}$ \\
Dinknesh & $76.8^{\mathrm{b}}$ & $79.4^{\mathrm{bc}}$ & 78.7 & $74.8^{\mathrm{e}}$ & $77.4^{\mathrm{b}}$ \\
Hidase & $77.7^{\mathrm{ab}}$ & $80.9^{\mathrm{ab}}$ & 76.5 & $76.2^{\mathrm{bc}}$ & $77.8^{\mathrm{b}}$ \\
Honqolo & $52.9^{\mathrm{c}}$ & $82.3^{\mathrm{a}}$ & 79.2 & $75.1^{\mathrm{de}}$ & $72.4^{\mathrm{c}}$ \\
King-bird & $76.5^{\mathrm{b}}$ & $82.1^{\mathrm{a}}$ & 82.2 & $77.1^{\mathrm{a}}$ & $79.5^{\mathrm{a}}$ \\
Local variety & $50.1^{\mathrm{c}}$ & $78.4^{\mathrm{c}}$ & 75.4 & $73.4^{\mathrm{f}}$ & $69.3^{\mathrm{c}}$ \\
Madda Walabu & $76.2^{\mathrm{b}}$ & $79.6^{\mathrm{bc}}$ & 79.6 & $75.5^{\mathrm{cd}}$ & $77.7^{\mathrm{b}}$ \\
Mekelle-3 & $76.8^{\mathrm{b}}$ & $81.3^{\mathrm{ab}}$ & 75.7 & $73.3^{\mathrm{b}}$ & $76.8^{\mathrm{b}}$ \\
Mekelle-4 & $80.5^{\mathrm{a}}$ & $82.4^{\mathrm{a}}$ & 79.6 & $71.5^{\mathrm{a}}$ & $78.5^{\mathrm{ab}}$ \\
Ogolcho & $80.1^{\mathrm{a}}$ & $82.3^{\mathrm{a}}$ & 81.4 & $73.5^{\mathrm{b}}$ & $79.3^{\mathrm{ab}}$ \\
Shorima & $79.9^{\mathrm{a}}$ & $82.6^{\mathrm{a}}$ & 76.1 & $75.9^{\mathrm{bc}}$ & $78.6^{\mathrm{ab}}$ \\
Sofumar & $80.2^{\mathrm{a}}$ & $82.6^{\mathrm{a}}$ & 79.0 & $73.5^{\mathrm{b}}$ & $78.8^{\mathrm{ab}}$ \\
Sorra & $80.4^{\mathrm{a}}$ & $81.8^{\mathrm{a}}$ & 80.7 & $76.3^{\mathrm{b}}$ & $79.8^{\mathrm{a}}$ \\
Tsehay & $77.0^{\mathrm{b}}$ & $80.8^{\mathrm{ab}}$ & 79.6 & $68.7^{\mathrm{b}}$ & $76.5^{\mathrm{b}}$ \\
Mean & 75.0 & 81.1 & 78.7 & 74.3 & 77.3 \\
CV (\%) & 12.8 & 1.1 & 4 & 0.4 & $7 . .^{\mathrm{b}}$ \\
\hline
\end{tabular}

King-bird showed consistent performance for TKW at Borena, recording 42.5, 40.7, 38.9 and $38.9 \mathrm{~g}$, respectively. On the other hand, TKW at Kelela is below 30 gram, except for variety Hidase and Sorra. There was mild cold and terminal moisture stresses at grain filling period at Kelela, which consequently affected the kernel size. TKW below 30 gram is classified as small kernelled wheat. In general, based on farmers' kernel boldness preference and breeders' TKW analysis, Danda'a, Ogolcho and King-bird yet again demonstrated their superiority at Legambo, Wogdie and Borena areas, while Hidase outfitted at Kelela and similar environments. Farmers' qualitative evaluations are not far-away from conventional breeders' technical evaluation, rather it strengthens and complements conventional breeders.

\section{Bread wheat varietal variation for hectoliter weight}

Hectoliter weight (HLW), density of clean kernels, is a good indicator of grain-soundness and hence used in grain grading. Varietal variation was observed for HLW among bread wheat varieties in all the testing environments, except at Borena (Table 7). However, most of the bread wheat varieties recorded acceptable HLW, except for local variety at Legambo and variety Tsehay at Kelela. Farmers' preferred varieties; Danda'a, Ogolcho and King-bird fulfilled the minimum HLW requirement.

\section{Genetic gain of farmers' selected varieties}

Varietal selection should come up with genetic improvement for the desirable trait(s). To examine whether farmers' selection brought genetic improvement for the economic and farmers' preferred traits or not, the response of selection for grain yield, kernel boldness and hectoliter weight of farmers' selected top-three bread wheat varieties were compared with the base population.

Farmers selected varieties exhibited genetic improvement over the base population for all the traits evaluated across environments, except for grain yield and hectoliter weight at Wogdie (Table 8). The low genetic gain for grain yield and hectoliter weight of farmers' selected varieties at Wogdie could be justified that the top-yielding varieties Mekelle-3, Mekelle-4 and Honqolo were not under farmers' preference list due to the undesirable traits they possessed. Farmers did not rely on a single trait, rather evaluated a variety from different agronomic and quality perspectives. Whereas, the mean grain yield of the top-three farmers selected bread wheat varieties showed genetic improvement over the base population by 354,488 and $496 \mathrm{Kg} \mathrm{ha}^{-1}$ at Legambo, Borena and Kelela, respectively. Hence, if farmers use these bread wheat varieties as seed source, their productivity could be improved. Kernel boldness is an important trait in bread wheat improvement. The selected bread wheat varieties confirmed genetic improvement in TKW over the base population by 2.8, 1.7, 3.6 and $2.4 \mathrm{~g}$ at Legambo, Wogdie, Borena and Kelela, in that order. Similarly, the selected bread wheat varieties also displayed genetic gain for HLW over the base population by $2.9,1.7$ and $1.3 \mathrm{Kg} \mathrm{hL}^{-1}$ at Legambo, Borena and Kelela, respectively (Table 8). This pieces of information illustrated that farmers had a superb evaluation and selection skills to identify superior bread wheat varieties for the economic and desirable traits, and their qualitative evaluation is in agreement with breeders' quantitative analysis. 
Table 8. Genetic gain of farmers' selected bread wheat varieties over the base population for grain yield and yield-related traits across locations.

\begin{tabular}{lccccccccc}
\hline \multirow{2}{*}{ District } & \multicolumn{3}{c}{ Mean grain yield $\left(\mathrm{Kg} \mathrm{ha}^{-1}\right)$} & \multicolumn{3}{c}{ Mean TKW $\mathbf{( g )}$} & \multicolumn{3}{c}{ Mean HLW $\left.\mathbf{~ ( K g ~ h L} \mathbf{~}^{-1}\right)$} \\
\cline { 2 - 10 } & $\mathbf{B P}^{*}$ & FSV & GG & BP & FSV & GG & BP & FSV & GG \\
\hline Legambo & 5437 & 5791 & 354 & 37.9 & 40.6 & 2.8 & 75.0 & 77.9 & 2.9 \\
Wogdie & 4725 & 4692 & -33 & 43.6 & 45.3 & 1.7 & 81.1 & 80.6 & -0.5 \\
Borena & 4897 & 5385 & 488 & 37.1 & 40.7 & 3.6 & 78.7 & 80.4 & 1.7 \\
Kelela & 2639 & 3135 & 496 & 26.3 & 28.7 & 2.4 & 74.3 & 75.6 & 1.3 \\
\hline
\end{tabular}

${ }^{*}$ Where, BP $=$ Base population (all the tested 15 bread wheat varieties), FSV = Farmers selected varieties and GG = Genetic gain of farmers selected bread wheat varieties over the base population.

Participating farmers in varietal development could be an input to incorporate farmers' preferred traits and varieties. From farmers' participation, conventional plant breeder has nothing to lose but much to gain in augmenting formal breeding technique (Ceccarelli et al., 2000). PVS facilities technological adoption. Thus, participating farmers in varietal development is not a matter of breeders' willingness rather it is a matter of decision to realize whether PVS or conventional breeding technique is more efficient for technological adoption. Regardless of breeders' choice, farmers are the one who ultimately makes the decision whether or not to adopt a new variety (Ceccarelli et al., 2000).

\section{Conclusion}

Identifying and analyzing farmers' desirable traits and weighing their degree of contribution to grain yield is very crucial to incorporate farmers' preferred traits for future bread wheat breeding and selection program. Farmers listed-down the most important agronomic traits that a superior bread wheat variety should possess and tallying the traits according to their contribution to grain yield. Then, they identified eight major quantitative and qualitative traits that is generally categorized as abiotic and biotic stress-related traits, yield-related and quality traits.

Farmers in the study area are extremely concerned about the recurrent frost episodes. Frost is generally lethal, especially when it occurs at early flowering stage and when it freezes for long periods of time. In addition, wheat rusts are the major leaf diseases that seriously impede productivity and production of wheat in the study area. Late onset, early termination and erratic distribution of rainfall coupled with recurrent frost episodes typify the major bread wheat growing areas of South Wollo, Ethiopia ensuing significant yield loss. Development of bread wheat varieties that flower before frosting period and that complete their physiological maturity earlier than the critical terminal moisture-stress period is very important. Hence, early maturity is an important trait in bread wheat breeding programs. Hence, frost and rust tolerance and earliness took the lion's-share of farmers' selection index.
Quantifying farmers' preferred traits would help to know the economic worth of the traits in crop improvement. Based on the degree of their contribution to the economic trait, breeders could design breeding and selection strategy.

It could be concluded that farmers have untapped lifelong breeding and selection experiences that conventional breeders should make use of it for future bread wheat improvement program. Farmers were very keen to qualitatively identify superior bread wheat varieties from different agronomic and quality perspectives, without destructive sampling. Their qualitative evaluation was in agreement with conventional breeders' quantitative evaluation and analysis. In a nutshell, farmers are not always recipients of information, rather they can be source of information, given their life-long agricultural experiences.

\section{CONFLICT OF INTEREST}

The authors declare that they have no conflict of interest.

\section{ACKNOWLEDGEMENTS}

The authors are very grateful to the host and the Farmers Research Group (FRG) who were actively involved in executing and evaluating the experiment. We are very indebted to the extension agents of each experimental site, without their enthusiastic commitment, the experiment may not be successful. We would like to thank our colleagues; Mr. Seyoum Teshome, Mr. Asmamaw Yimer, Mr. Tesfaye Desale, Mr. Desalegn Getu and Mr. Admassie Kassaw for their keen support in executing the experiment and data collection.

\section{REFERENCES}

Abebe, G., Assefa, T., Harrun, H., \& Mesfine, T. (2005). Participatory selection of drought tolerant maize varieties using mother and baby methodology: A case study in the semi arid zones of the central rift valley of Ethiopia. In African Crop Science Conference Proceedings (Vol. 7, pp. 1479-1485).

Basavaraj, G., Parthasarathy Rao, P., Achoth, L., Pokharkar, V. 
G., Gupta, S. K., \& Ashok Kumar, A. (2015). Understanding Trait Preferences of Farmers for Post-Rainy Sorghum and Pearl Millet in India-A Conjoint Analysis. Indian Journal of Agricultural Economics, 70(1), 130-143.

Belay, G., Tefera, H., Tadesse, B., Metaferia, G., Jarra, D., \& Tadesse, T. (2006). Participatory variety selection in the Ethiopian cereal tef (Eragrostis tef). Experimental Agriculture, 42(1), 91-101.

Ceccarelli, S., Grando, S., Singh, M., Michael, M., Shikho, A., Al Issa, M., Al Saleh, A., Kaleonjy, G., Al Ghanem, S. M., Al Hasan, A. L., \& Dalla, H. (2003). A methodological study on participatory barley breeding II. Response to selection. Euphytica, 133(2), 185-200.

Ceccarelli, S., Grando, S., Tutwiler, R., Baha, J., Martini, A. M., Salahieh, H., Goodchild, A., \& Michael, M. (2000). A methodological study on participatory barley breeding I. Selection phase. Euphytica, 111(2), 91-104.

Central Statistical Agency (CSA) (2016). Agricultural sample survey, Volume I. Report on area and production of major crops.

Chambers, R. (2005). Rural appraisal: rapid, relaxed, participatory: Vikas publishing house.

Chimdesa, O., Aseffa, K., \& Alemu, S. (2018). Participatory Variety Selection of Improved Bread Wheat Varieties for Moisture Stress Areas of Guji Zone, Southern Oromia. International Journal of Research in Agriculture and Forestry, 5(4), 1-6.

Gashaw, A., Mohammed, H., \& Singh, H. (2007). Genetic divergence in selected durum wheat genotypes of Ethiopian germplasm. African Crop Science Journal, 15(2), 67-72.

Gashaw, A., Mohammed, H., \& Singh, H. (2010). Genotypic variability, heritability, genetic advance and associations among characters in Ethiopian durum wheat (Triticum durum desf.) accessions. East African Journal of Sciences, 4(1), 2733.

lqbal, M., Navabi, A., Salmon, D., Yang, R. C., \& Spaner, D. (2006). A genetic examination of early flowering and maturity in Canadian spring wheat. Canadian Journal of Plant Science, 86(4), 995-1004.

Mancini, C., Kidane, Y. G., Mengistu, D. K., Pè, M. E., Fadda, C., \& Dell'Acqua, M. (2017). Joining smallholder farmers' traditional knowledge with metric traits to select better varieties of Ethiopian wheat. Scientific reports, 7(9120), 11p.

Mustafa, Y., Grando, S., \& Ceccarelli, S. (2006). Assessing the benefits and costs of participatory and conventional barley breeding programs in Syria. ICARDA report for a study supported by the International Development Research Centre. Pp. 1-54.
Namara, R. \& Manig, W. (2000). Participatory bread wheat breeding in Ethiopia: A socio-economic assessment. Deutscher Tropentag, Pp. 1-15.

Nkongolo, K., Chinthu, K., Malusi, M., \& Vokhiwa, Z. (2008). Participatory variety selection and characterization of Sorghum (Sorghum bicolor (L.) Moench) elite accessions from Malawian gene pool using farmer and breeder knowledge. African Journal of Agricultural Research, 3(4), 273-283.

Orawu, M., Obuo, P., \& Omadi, R. (2013). Participatory variety selection to enhance cowpea variety development and selection in northern region of Uganda. Uganda Journal of Agricultural Sciences, 14(1), 57-73.

Pandit, D., Islam, M., Harun-ur-Rashid, M., \& Sufian, M. (2007). Participatory variety selection in wheat and its impact on scaling-up seed dissemination and varietal diversity. Bangladesh Journal of Agricultural Research, 32(3), 473-486.

Paulsen, G. M., Heyne, E. G., \& Wilkins, H. D. (1982). Spring freeze injury to Kansas wheat (No. 83-922105. CIMMYT).

Seifu, E., Mekibib, F., \& Dessalegn, T. (2018). Performance and farmers selection criteria Evaluation of Improved Bread Wheat Varieties. African Journal of Agricultural Research, 13(44), 2477-2498.

Singh, Y. P., Nayak, A. K., Sharma, D. K., Gautam, R. K., Singh, R. K., Singh, R., Mishra, V.K., Paris, T., \& Ismail, A. M. (2014). Farmers' participatory varietal selection: A sustainable crop improvement approach for the 21st century. Agroecology and Sustainable Food Systems, 38(4), 427-444.

Sperling, L., Loevinsohn, M., \& Ntabomvura, B. (1993). Rethinking the farmer's role in plant breeding: Local bean experts and on-station selection in Rwanda. Experimental Agriculture, 29(4), 509-519.

Vom Brocke, K., Trouche, G., Weltzien, E., Barro-Kondombo, C. P., Gozé, E., \& Chantereau, J. (2010). Participatory variety development for sorghum in Burkina Faso: Farmers' selection and farmers' criteria. Field Crops Research, 119(1), 183-194.

Witcombe, J. R., Joshi, A., Joshi, K. D., \& Sthapit, B. (996). Farmer participatory crop improvement. I. Varietal selection and breeding methods and their impact on biodiversity. Experimental Agriculture, 32(4), 445-460.

Witcombe, J., \& Virk, D. 1997. New directions for public sector variety testing. New Seed and Old Laws. Regulatory reform and the diversification of national seed systems.(Tripp $R$ ed.). London, UK: Intermediate Technology Publications. Pp. 59-87. 